\title{
Diabetes is associated with increased and persistent myocardial edema in infarct segment post acute myocardial infarction
}

\author{
Mohammad I Zia*, Nilesh R Ghugre, Kim A Connelly, Bradley H Strauss, Alexander J Dick, Graham Wright \\ From 15th Annual SCMR Scientific Sessions \\ Orlando, FL, USA. 2-5 February 2012
}

\section{Summary}

Our study demonstrates that diabetic patients have increased myocardial edema in the infarct segment at an early time point post acute myocardial infarction which persists till the subacute phase. This may lead to deleterious left ventricular remodeling and worse outcome in these patients.

\section{Background}

Diabetes is associated with worse left ventricular remodeling and poor prognosis in patients post acute myocardial infarction (AMI). The impact of diabetes on microvascular injury parameters including myocardial edema and hemorrhage post AMI is unknown. Our objective was to characterize the evolution of myocardial edema and hemorrhage post AMI in patients with and without diabetes.

\section{Methods}

Sixty patients were enrolled post AMI and underwent cardiac magnetic resonance on a GE Signa Excite, 1.5T scanner with a 8-channel receive coil at 48 hours and 3 weeks. T2 maps were computed from a previously validated cardiac-gated spiral imaging sequence with T2 preparations yielding $\mathrm{TEs}=2.9,24.3,88.2,184.2 \mathrm{~ms}$ to assess myocardial edema. The $\mathrm{T}^{*}$ sequence was a multiecho acquisition with 8 echoes (between 1.4 and $12.7 \mathrm{~ms}$ ) acquired at $\mathrm{TR}=14.6 \mathrm{~ms}$. Delayed hyperenhancement was also performed. We retrospectively reviewed and stratified patients into those that did and did not have diabetes (type 1 or type 2 ).

Sunnybrook Health Sciences Centre, Toronto, ON, Canada

\section{Results}

We compared 15 diabetics versus 45 non-diabetics (Table 1). Baseline characteristics including age, gender, symptom to balloon time, door to balloon time, glycoprotein IIb/IIIa inhibitor use, and thrombus aspiration use were similar in both groups. The mean T2 was higher in the infarct segment (IS) compared to remote segment (RS) in both patient groups (diabetics: $59.3 \mathrm{~ms}$ vs $41.3 \mathrm{~ms}, \mathrm{p}<0.0001$ vs non-diabetics: $52.9 \mathrm{~ms}$ vs $40.1 \mathrm{~ms}$, $\mathrm{p}<0.0001)$. The mean $\mathrm{T} 2 *$ was similar in the IS compared to RS in both diabetics $(32.1 \mathrm{~ms}$ vs $38.0 \mathrm{~ms}$; $\mathrm{p}=0.11)$ and non-diabetics $(33.9 \mathrm{~ms}$ vs $36.7 \mathrm{~ms} ; \mathrm{p}=0.09)$. The mean T2 was significantly higher in the IS of diabetic patients versus non-diabetics $(59.3 \mathrm{~ms}$ vs $52.9 \mathrm{~ms}$; $\mathrm{p}=0.03)$. The mean $\mathrm{T}^{*}$ was equivalent in the IS of both patient groups $(32.1 \mathrm{~ms}$ vs $33.9 \mathrm{~ms} ; \mathrm{p}=0.59)$.

At 3 weeks, the mean T2 remained significantly higher in the IS of diabetic patients versus non-diabetics $(56.6 \mathrm{~ms}$ vs $51.2 \mathrm{~ms} ; \mathrm{p}=0.04)$. At this time interval, the mean $\mathrm{T} 2$ * was equivalent in the IS of both patient groups ( $37.1 \mathrm{~ms}$ vs $37.0 \mathrm{~ms}$; $\mathrm{p}=0.96$ ).

\section{Conclusions}

Our study demonstrates that diabetic patients have increased myocardial edema in the IS at an early time point post AMI which persists till the subacute phase (3 weeks). The degree of myocardial hemorrhage does not appear to be influenced by diabetes status. Diabetes increases the area at risk during AMI which may lead to deleterious left ventricular remodeling and worse outcome in these patients.

\section{Funding}

Dr. Connelly is supported by a Heart and Stroke Foundation of Canada Phase 1 Clinician Scientist Award. Dr. 
Table 1

\begin{tabular}{ccc}
\hline Baseline characteristic & $\begin{array}{c}\text { Diabetic } \\
(\mathrm{n}=15)\end{array}$ & $\begin{array}{c}\text { Non-diabetic } \\
(\mathrm{n}=45)\end{array}$ \\
\hline Mean age, years & 59.5 & 59.9 \\
Male, \% & $2(13)$ & $5(11)$ \\
Anterior MI, \% & $7(47)$ & $19(42)$ \\
Mean peak CK, IU/L & 2521 & 2134 \\
Symptom to balloon time, & 452 & 373 \\
minutes & & \\
Door to balloon time, minutes & 93.1 & 79.8 \\
LVEF, \% & 45.3 & 44.9 \\
Infarct size, \% & 23.2 & 22.5 \\
\hline
\end{tabular}

Wright receives research funding from GE Healthcare. Dr. Dick is supported by the Heart and Stroke Foundation of Canada. This work was supported in part by a Canadian Institutes of Health Research (CIHR) operating grant and the Ontario Research Fund.

Published: 1 February 2012

doi:10.1186/1532-429X-14-S1-P29

Cite this article as: Zia et al: Diabetes is associated with increased and persistent myocardial edema in infarct segment post acute myocardial infarction. Journal of Cardiovascular Magnetic Resonance 2012 14(Suppl 1): P29.

Submit your next manuscript to BioMed Central and take full advantage of:

- Convenient online submission

- Thorough peer review

- No space constraints or color figure charges

- Immediate publication on acceptance

- Inclusion in PubMed, CAS, Scopus and Google Scholar

- Research which is freely available for redistribution 